\title{
TASAWUF DAN PROBLEMATIKA MODERNITAS: MENIMBANG MAQAMAT DAN AHWAL ABU NASHR AS-SARRAJ
}

\author{
Arrasyid \\ Universitas Islam Negeri (UIN) Sunan Kalijaga Yogyakarta, arrasyid350@gmail.com \\ \begin{tabular}{l|l|l|} 
Diterima: 04 Januari 2020 & Direvisi: 29 April 2020 & Diterbitkan: 30 Juni 2020 \\
\hline
\end{tabular}
}

\begin{abstract}
Modernity with the sparkling development of science and technology is not bringing people closer to the happiness of life, but instead increasingly becoming anxious because of the luxury of life that he achieved. In this context, Sufism is often believed to be an oasis for the problems of modernity. The purpose of this study is to describe and review the concepts of maqamat and ahwal in Sufism presented by Abu Nashr asSarraj and analyze their relevance to modern human problems. This research is a library research, with the data source in the form of library materials such as books, journals and scientific articles. In accordance with the type, the data collection in this study uses library research methods that are analyzed using the method of description and data analysis. The results of this study indicate that in the view of Abu Nashr as-Sarraj, maqamat is divided into seven levels: taubat, wara', zuhud, fakir, sabar, tawakal, and ridha. As for the ahwal is divided into: muraqabah, mahabbah, khauf, raja', syauq, 'uns, tuma'ninah, musyahadah, and yaqin. Maqamat and ahwal in Sufism is a method in Sufism that can be used as an alternative offer and guidelines for modern bumans to achieve the ultimate closeness to Allah SWT in order to obtain true happiness.
\end{abstract}

Keywords: Sufism, Abu Nashr as-Sarraj, Maqamat, Abwal, Modernity.

\begin{abstract}
Abstrak
Modernitas dengan gemerlap perkembangan sains dan teknologinya bukannya membawa manusia mendekati kebahagiaan hidup, melainkan sebaliknya kian dihinggapi rasa cemas justru akibat kemewahan hidup yang diraihnya. Pada konteks ini, tasawuf seringkali diyakini dapat menjadi oase bagi problematika modernitas tersebut. Tujuan kajian ini adalah untuk mendeskripsikan dan mengulas konsep maqamat dan abwal dalam tasawuf yang diketengahkan oleh $\mathrm{Abu} \mathrm{Nashr}$ as-Sarraj dan menganalisis relevansinya dengan problematika manusia modern. Penelitian ini merupakan penelitian pustaka (library research), dengan sumber datanya berupa bahan pustaka seperti buku, jurnal dan artikel ilmiah. Sesuai dengan jenisnya maka pengumpulan data dalam penelitian ini menggunakan metode riset kepustakaan yang dianalisis menggunakan metode deskripsi dan analisis data. Hasil penelitian ini menunjukkan bahwa dalam pandangan Abu Nashr as-Sarraj, maqamat terbagi ke dalam tujuh tingkatan: taubat, wara', zuhud, fakir, sabar, tawakal, dan ridha. Adapun abwal terbagi menjadi: muraqabah, mahabbah, khauf, raja', syauq, 'uns, tuma'ninah, musyahadah, dan yakin. Maqamat dan ahwal dalam tasawuf merupakan metode dalam tasawuf yang dapat dijadikan sebagai tawaran alternatif dan pedoman manusia modern untuk mencapai kedekatan yang hakiki kepada Allah SWT demi memperoleh kebahagiaan sejati.

Kata Kunci: Tasawuf, Abu Nashr as-Sarraj, Maqamat, Abwal, Modernitas.
\end{abstract}




\section{PENDAHULUAN}

Abad 20 adalah periode menentukan dalam perkembangan intelektualisme, khususnya dalam bidang agama. ${ }^{1}$ Modernitas dengan gemerlap perkembangan sains dan teknologinya bukannya membawa manusia mendekati kebahagiaan hidup, melainkan sebaliknya kian dihinggapi rasa cemas justru akibat kemewahan hidup yang diraihnya. Pada konteks ini, tasawuf seringkali diyakini dapat menjadi oase bagi problematika modernitas tersebut. ${ }^{2}$

Islam sebagai suatu ajaran memiliki khazanah keilmuan yang amat luas, salah satunya khazanah keilmuan tasawuf yang selalu sangat menarik untuk dijadikan bahan diskusi ataupun penelitian bagi yang ingin menggeluti dunia mistik dalam Islam. Sama halnya dengan yang terdapat pada agama lain, tasawuf merupakan sebuah fenomena asketis keagamaan yang dianggap antimainstream karena memiliki cara tersendiri dalam mengekspresikan pengalaman keagamaan penganutnya. ${ }^{3}$

Tasawuf adalah jalan atau cara untuk mendekatkan diri kepada Allah SWT. dengan cara mempraktekkan konsep-konsep yang ada dalam tasawuf. Konsep-konsep yang ada dalam tasawuf mengarahkan manusia atau sufi untuk berada sedekat mungkin dengan Allah SWT. Tasawuf juga merupakan rangkaian eksperimen jiwa dalam menempuh jalan penyucian dan penempaan

${ }^{1}$ Apria Putra, "Ulama Dan Karya Tulis: Diskursus KeIslaman Di Minangkabau Awal Abad 20," Fuaduna: Jurnal Kajian Keagamaan Dan Kemasyarakatan 1, no. 2 (2017): 134 47,

https://doi.org/http://dx.doi.org/10.30983/fuaduna.v1i2. 434.

2 Zulfan Taufik, "The Youth and The Primacy against Religious Radicalism through the Organization of Mahasiswa Ahlith Thariqah Al Mu'tabarah An Nahdliyyah (MATAN) in Indonesia," TEOSOFI: Jurnal Tasawuf Dan Pemikiran Islam 9, no. 1 (June 1, 2019): 109-30, https://doi.org/10.15642/teosofi.2019.9.1.109-130; Dedy Irawan, "Tasawuf Sebagai Solusi Krisis Manusia Modern: Analisis Pemikiran Seyyed Hossein Nasr," Tasfiyah 3, no. 1 (February 2019):

https://doi.org/10.21111/tasfiyah.v3i1.2981.

3 Mariasusai Dhavamony, Fenomenologi Agama (Yogyakarta: Penerbit Kanisius, 1995), 285-87. rohani yang dituntun oleh kerinduan kepada Allah. Dalam tasawuf ada maqamat dan abwal. Maqamat adalah konsep dalam tasawuf yang menunjukkan kedudukan spiritual seorang sufi di mata Allah. Maqamat ini sifatnya tentu sangat subjketif, Karena berdasarkan pengalaman spiritual masing-masing sufi. Begitupun dengan ahwal umumnya buku-buku tasawuf memiliki subjektifitas sendiri dalam merumuskan kondisi spiritual atau abwal.

Baik maqamat maupun abwal adalah konsep tasawuf yang bisa dicapai dan dirasakan oleh semua orang, karena ia merupakan step by step mengikuti alur maqamat yang dihadirkan dalam kajian tasawuf. Setelah manusia bisa melewati step by step maqamat tasawuf maka Allah akan memberi ia kondisi-kondisi spiritual tentang pengalaman dengan Tuhan. Selain itu, konsep-konsep tasawuf ini, atau tepatnya maqamat dan abwal ini, tentu bukanlah hal yang baru dalam dunia tasawuf. Sejak tasawuf ada maka konsep inipun tentunya hadir. Melihat pada masa sekarang apakah masih relevan konsep tersebut dengan zaman sekarang sehingga bisa dipraktekan oleh siapapun yang ingin merasakan kedekatan dan pengalaman spiritual dengan Tuhan. Maka, oleh sebab itu, penting kiranya untuk mengetahui bagaimana maqamat dan abwal dalam tasawuf dan relevansinya dengan kehidupan sekarang ini.

$$
\text { Penelitian ini adalah penelitian }
$$
kepustakaan (librabry research) dengan mengkaji literatur-literatur tasawuf, terlebih dari karyakarya Abu Nashr As-Sarraj sebgai sumber primernya. Untuk menganalisis datanya, maka digunakan metode deskripsi, interpretasi, dan analisis yakni metode dalam bentuk deskripsi agar penulis mampu memahami dan memberikan gambaran yang jelas mengenai permasalahan yang terkait dengan kajian ini. Dan metode analisis digunakan agar penulisan ini lebih sistematis pada permasalahan yang akan dibahas dalam penelitian ini. 


\section{MAQAMATTASAWUF SEBAGAI TANGGA SPIRITUAL}

Istilah maqam (jamak: maqamat), sebagaimana juga abwal dipahami secara berbedabeda oleh para sufi sendiri. Meskipun demikian semuanya sepakat memahami maqamat bermakna kedudukan seorang perjalan sprititual di hadapan Allah yang diperoleh melalui kerja keras beribadah, bersungguh-sungguh melawan hawa nafsu (mujahadab) dan latihan-latihan keruhanian (riyadhah) sehingga mencapai keluhuran budi pekerti (adab). ${ }^{4}$ Bahkan maqamat bisa diartikan sebagai jalan spiritual yang harus dilalui para sufi dalam menacapai tujuan luhurnya, melalui proses pensucian jiwa terhadap kecenderungan materi agar kembali ke jalan Tuhan. ${ }^{5}$

Namun, para sufi sepakat bahwa maqamat sebagai suatu tahap adab kepada Allah dengan bermacam usaha yang diwujudkan untuk satu tujuan pencarian dan ukuran tugas masing-masing yang berada dalam tahapnya sendiri ketika dalam kondisi tersebut, serta tingkah laku riyadhah menuju kepada-Nya. ${ }^{6}$ Lebih mudahnya, maqamat adalah tahap atau titik pemberhentain untuk menacapai tasawuf yang harus dilalui satu demi satu oleh salik.

Adapun menurut al-Hujwiri (w. $465 \mathrm{H}$ / 1072 M), "maqamat merupakan keberadaan seseorang di jalan Allah. Lalu, ia memenuhi kewajiban-kewajiban yang berkaitan dengan maqam itu serta menjaganya hingga ia mencapai kesempurnaannya, sejauh berada dalam kekuatan manusia." Adapun menurut Imam al-Qusyairy an-Naisabury menjelaskan "maqam adalah tahapan adab (etika) seorang hamba dalam wushul kepadaNya dengan macam upaya, di-wujud-kan dengan

4 Haidar Bagir, Buku Saku Tasawuf (Bandung: Mizan, 2005), 121.

5 Moenir Nahrowi Tohir, Menjelajah Eksistensi Tasawuf Meniti Jalan Menuju Tuhan (Jakarta: PT As-Salam Sejahtera, 2012), 93.

${ }^{6}$ Imam al-Qusyairy, Risalah Qusyairyah: Induk Imu Tasawuf, Terj. Mohammad Luqman Hakiem (Surabaya: Risalah Gusti, 2014), 34.

${ }^{7}$ Media Zainul Bahri, Tasawuf Mendamaikan Dunia (Jakarta: Erlangga, 2010), 84-85. suatu tujuan pencarian". dan ukuran tugas Masing-masing berada dalam tahapannya sendiri ketika dalam kondisi tersebut, serta tingkah laku riyadhah menuju kepada-Nya. ${ }^{8}$ Berdasarkan penjelasan di atas sederhananya maqamat adalah kedudukan atau posisi seseorang hamba di hadapan Allah yang dia selalu istiqamah pada kedudukan tersebut dan berusaha untuk meningkatkannya sehingga mencapai tingkatan derajat yang puncak.

Adapun maqamat tersebut yaitu:

\section{Taubat}

Tahap awal maqamat di dalam tasawuf adalah taubat, "pertaubatan".' Secara etimologi taubat berasal dari kata taba, yatubu, taubatan artinya kembali. ${ }^{10}$ Taubat berarti berpaling dari dosa, untuk menghilangkan segala keprihatinan duniawi. ${ }^{11}$ Taubat juga berarti kembali dari sesuatu yang dicela oleh syara menuju sesuatu yang dipuji oleh-Nya. ${ }^{12}$ Menurut Qamar Kailani dalam bukunya Fi at-Tashawnuf al-Islami, yang dikutip dari buku Ilmu Tasawnf karangan M. Solihin dan Rosihon Anwar "taubat adalah rasa penyesalan yang sungguh-sungguh dalam hati disertai permohonan ampun serta meninggalkan segala perbuatan yang menimbulkan dosa." ${ }^{13}$ Sedangkan menurut Fethullah Gulen "taubat adalah bertawajuh kepada Allah dengan penuh penyesalan dan rasa perih di dalam hati seraya mengakui semua kesalahan, meratap dalam penyesalan, dan tekad untuk meninggalkan kesalahan yang lalu." ${ }^{14}$ Berdasarkan penjelasan di

\footnotetext{
8 al-Qusyairy, Risalah Qusyairyah: Induk Imu Tasawnf, Terj. Mohammad Luqman Hakiem, 23.

9 Annemarie Schimmel, Mystical Dimensions of Islam (North Carolina: The University of North Carolina Press, 1975), 109.

10 Abuddin Nata, Akblak Tasawnf Dan Karakter Mulia (Jakarta: Rajawali Pers, 2013), 171. Islam, 23.

11 Annemarie Schimmel, Mystical Dimensions of

12 Bahrun Rifi and Hasan Mud'is, Filsafat Tasawuf (Bandung: CV Pustaka Setia, 2010), 202.

13 M. Solihin and Rosihon Anwar, Imu Tasawuf (Bandung: CV Pustaka Setia, 2008), 78.

14 Muhammad Fethullah Gulen, Tasawuf Untuk Kita Semua: Menapaki Bukit-Bukit Zamrud Kalbu Melalui
} 
atas sederhananya taubat adalah menyesali kesalahan dengan meminta ampun kepada Allah dengan berkomitmen tidak akan mengulanginya lagi.

\section{Wara'}

Secara bahasa wara' artinya shaleh, menjauhkan diri dari perbuatan dosa. Kata ini selanjutnya mengandung arti menjauhi hal-hal yang tidak baik. Al-Ustaz al-Imam r.a berkata, "yang dimaksud wara' adalah meninggalkan hal-bal yang syubhat." Ibrahim bin Adham juga memberikan komentarnya yang dimaksud dengan wara', yaitu "meninggalkan hal-hal yang syubhat dan yang tidak pasti atau tidak dikehendaki, yakni meninggalkan hal-hal yang tidak berfaedah." "15 Sedangkan menurut Fethullah Gulen wara' adalah "menghindari segala hal yang tidak baik, tidak sesuai, dan tidak perlu, serta berhati-hati terhadap hal-hal yang diharamkan dan dilarang". Wara juga berarti menghindari segala bentuk syubhat karena takut terperosok dalam hal yang haram.Semua ini sesuai dengan sebuah kaidah yang berbunyi, "Tinggalkanlah yang meragukanmu menuju yang tidak meragukanmu."16

\section{Zubud}

Secara bahasa zuhud berarti tidak condong kepada sesuatu yang bersifat keduniawian. ${ }^{17}$ Adapun secara istilah, menurut Ibnu Qayyim al-Jauziyah zuhud adalah "perjalanan hati dari kampung dunia dan menempatkannya di akhirat". ${ }^{18}$ Suatu perjalanan tentunya membutuhkan bekal agar lebih

Istilah-Istilah Dalam Praktik Sufisme Jakarta: Republika, 2013), 25.

15 al-Qusyairy, Risalab Qusyairyah: Induk Ilmu Tasawuf, Terj. Mohammad Luqman Hakiem, 146.

16 Gulen, Tasawnf Untuk Kita Semua: Menapaki Bukit-Bukit Zamrud Kalbu Melalui Istilah-Istilah Dalam Praktik Sufisme.

${ }^{17}$ Mahmud Yunus, Kamus Arab (Jakarta: Hidakarya Agung, 1990), 362.

18 Ibnu Qayyim Al-Jauziyah, Madarijus Salikin: Pendakian Menuju Allah Penjabaran Konkrit "Iyyaka Na'budu Wa Iyyaka Nasta’in” (Jakarta: Pustaka al-Kautsar, 2017), 195. bertenaga sehingga perjalanan dapat dinikmati. Modal bekal inilah sebagai modal manusia untuk bisa bertahan dalam hidup ini sehingga bisa menjalani hidup dengan tenang dan bahagia sehingga fokus mencapai akhirat. Adapun Ibnu Taimiyyah berpendapat bahwa "zuhud itu berarti meninggalkan apa-apa yang tidak bermanfaat untuk kepentingan akhirat". ${ }^{19}$ Sedang menurut Hamka sebagai tokoh tasawuf Modern mengatakan bahwa Zuhud akan dunia itu adalah sudi miskin, sudi kaya, sudi tidak mempunyai uang sepeserpun juga, sudi jadi miliuner, tetapi harta itu tidak menjadi alasan buat dia melupakan Tuhan, atau lalai dari kewajiban. ${ }^{20}$ Dengan demikian dapat dipahami, bahwa zuhud itu adalah hati dan pikiran tetap bahagia bersama dunia dan tidak menganggu hubungan untuk dekat dengan Allah. Sederhananya zuhud yaitu kedekatan dengan dunia tidak menganggu kedekatan dengan Allah.

\section{Fakir}

Secara bahasa fakir biasanya diartikan sebagai orang yang berhajat, orang yang butuh atau orang miskin. Adapun dalam pandangan sufi fakir adalah tidak meminta lebih dari apa yang telah ada pada diri kita. Tidak meminta rezeki kecuali hanya untuk dapat menjalankan kewajiban-kewajiban. Tidak meminta walaupun tidak ada pada diri kita, kalau diberi dia terima. Dia tidak meminta dan tidak juga menolak apabila diberikan kepadanya. ${ }^{21}$ Fethullah Gulen mengartikan "bahwa fakir adalah kesadaran atas kebutuhan kepada Allah semata dan hidup dalam kesadaran atas kecukupan pada makhluk". ${ }^{22}$ Yahya bin Mu'adz ketika ditanya tentang hakikat kefakiran dia menjawab bahwa seseorang tidak

\footnotetext{
${ }^{19}$ Rifi and Mud'is, Filsafat Tasawuf, 207.

${ }^{20}$ Hamka, Tasawuf Modern: Bahagia Itu Dekat Dengan Kita Ada Di Dalam Diri Kita (Jakarta: Republika, 2015), 263.

${ }^{21}$ Nata, Akblak Tasawuf Dan Karakter Mulia, 173.

22 Gulen, Tasawnf Untuk Kita Semua: Menapaki Bukit-Bukit Zamrud Kalbu Melalui Istilab-Istilah Dalam Praktik Sufisme, 297.
} 
butuh lagi selain Allah, dan tanda kefakiran adalah tidak adanya harta benda. ${ }^{23}$

\section{Sabar}

Sabar secara bahasa adalah bertahan atau menahan, bertahan dan menahan diri dari rasa gelisah, rasa cemas dan rasa amarah, menahan lidah dari keluh kesah, menahan anggota tubuh dari kekacauan. ${ }^{24}$ Menurut Fethullah Gulen "sabar adalah tabah menjalani penderitaan dan nestapa ketika menghadapi berbagai kejadian yang sulit untuk dihadapi dan sulit untuk dihindari”. Abu Muhammad Ahmad al-Jurairy menjelaskan bahwa sabar adalah suatu keadaan yang tidak membedakan keadaan bahagia atau menderita, disertai dengan ketenangan jiwa dan pikiran dalam keduanya. Orang bersikap sabar adalah akan mengalami kedamaian dan ketenangan ketika menerima cobaan, meskipun dengan adanya kesadaran akan beban penderitaan. ${ }^{25}$

\section{Tawakekal}

Tawakkal diambil dari kata wakalah yang berarti at-Tafwidl (penyerahan) dan al-i'timad (penyandaran). Seperti kalimat: wakkala amrubu ilaa fulaanin (dia menyerahkan dan menyandarkan urusannya kepada seseorang). Jadi, secara etimologi tawakkal adalah menyandarkan hati sepenuhnya hanya kepada wakil yang Maha Mewakili dan Maha Haq yaitu (Allah). ${ }^{26}$ Adapun secara terminologi menurut Abu Turab anNakhsyabi seperti yang dikutip oleh Abu Nashr as-Sarraj berpendapat bahwa tawakkal adalah mengabdikan diri untuk beribadah kepada Allah dan hatinya hanya terkait dengan Allah SWT.dan selalu tenang dalam kecukupan. Jika diberi dia

23 al-Qusyairy, Risalab Qusyairyah: Induk Ilmu Tasawuf, Terj. Mohammad Luqman Hakiem.

24 Al-Jauziyah, Madarijus Salikin: Pendakian Menuju Allah Penjabaran Konkrit "Iyyaka Na'budu Wa Iyyaka Nasta'in," 259.

25 al-Qusyairy, Risalah Qusyairyah: Induk Ilmu Tasawnf, Terj. Mohammad Luqman Hakiem, 211.

26 As-Sayid Abu Bakar Ibn Muhammad Syata, Menapak Jejak Kaum Sufi (Surabaya: Dunia Ilmu, n.d.), 80. akan bersyukur, jika tidak diberi dia tetap bersabar dan menerima dengan ikhlas takdir yang telah ditentukan. ${ }^{27}$ Ketika Ibnu Atha' ditanya hakikat tawakkal, ia menjelaskan, "tawakkal adalah kehendaknya hasrat yang mengebu-gebu terhadap perkara duniawi tidak muncul dalam dirimu, meskipun engkau sangat membutuhkannya, dan bahwa kehendaknya engkau senantiasa bersikap qana'ah dengan Allah, meskipun engkau tergantung pada kebutuhan-kebutuhan duniawi itu." 28

\section{Ridha}

Ridha artinya ikhlas menerima apapun yang telah ditentukan dan ditakdirkan oleh Allah kepadanya. Keikhlasan mereka dalam menerima semata-mata karena Allah. Orang yang telah memiliki sifat "ridha" tidak akan mudah bimbang atau kecewa atas pengorbanan yang menimpanya, tidak merasa menyesal dalam hidup kekurangan, tidak iri hati atas kelebihan-kelebihan yang telah dimiliki oleh orang lain, karena mereka kuat dan tetap berpegang pada aqidah yang berkaitan dengan qadha dan qadhar yang semuanya itu dari Allah. ${ }^{29}$ Dalam literatur yang lain ridha adalah ketentraman hati dan ketenangan jiwa terhadap keputusan dan ketetapan takdir Allah SWT. serta kemampuan dirinya untuk menyikapinya dengan sabar, terhadap derita, nestapa, dan kesulitan yang muncul darinya yang dirasakan oleh jiwa. ${ }^{30} \mathrm{Ibnu}$ Ujaibah berkata bahwa "ridha adalah menerima kehancuran dengan wajah tersenyum, atau bahagianya hati ketika ketetapan terjadi, atau tidak memilih-milih apa yang telah diatur dan

${ }^{27}$ Abu Nashr as-Sarraj, Al-Luma': Rujukan Lengkap Ilmu Tasawuf (Surabaya: Risalah Gusti, 2002), 106.

28 al-Qusyairy, Risalah Qusyairyah: Induk Ilmu Tasawuf, Terj. Mohammad Luqman Hakiem, 181.

29 Mustafa Zahri, Kunci Memahami Ilmu Tasawuf, (Surabaya: PT Bina Ilmu, 1979), 71-72.

30 Gulen, Tasawnf Untuk Kita Semua: Menapaki Bukit-Bukit Zamrud Kalbu Melalui Istilah-Istilah Dalam Praktik. Sufisme, 197. 
ditetapkan oleh Allah, atau lapang dada dan tidak mengingkari apa-apa yang datang dari Allah." 31

\section{AHWAL TASAWUF SEBAGAI KEADAAN SPRITUAL}

Adapun hal (jamak: abwal) adalah suasana atau keadaan yang menyelimuti kalbu, yang diciptakan (sebagai hak prerogatif) Allah dalam hati mansuia, tanpa sang sufi meminta atau mampu menolak keadaan itu apabila datang dan mempertahankannya apabila pergi. ${ }^{32}$ Jadi abwal adalah suatu anugerah pemberian dari Allah Swt karena ketaatan manusia dan beribadahnya secara terus menerus. ${ }^{33}$

Adapun abwal tasawuf tersebut yaitu:

\section{Muraqabah (Mawas Diri)}

Menurut Imam al-Qusyairy an-Naisabury secara bahasa muraqabah "adalah mengamati tujuan. Sedangkan secara terminologi muraqabah yaitu keyakinan seorang sufi dengan kalbunya bahwasanya Allah SWT". melakukan pengamatan kepadanya dalam gerak dan diamnya sehingga membuat ia mengamati pekerjaan dan hukumhukum-Nya. ${ }^{34}$ sedangkan menurut Abu Nashr asSarraj muraqabab adalah pengetahuan dan keyakinan seorang hamba kepada Allah, bahwa Allah SWT selalu Melihat apa yang ada didalam hati dan nuraninya dan Maha Mengetahui. Maka dalam kondisi apapun dia selalu terus-menerus meneliti dan mengkoreksi bersitan-bersitan hati atau pikiran-pikiran tercela yang hanya akan menyibukkan hati sehingga lupa mengingat Allah. ${ }^{35}$

31 Syaikh 'Abdul Qadir Isa, Hakekat Tasawnf (Jakarta: Qisthi Press, 2005), 251-52.

32 Bagir, Buku Saku Tasawnf, 121.

33 Syaikh Ibn 'Atha'illah as-Sakandari, Kitab AlHikam: Petuah-Petuah Agung Sang Guru, Terj. Ismail Ba'adillah (Jakarta: Khatulistiwa Press, 2012), 58.

34 al-Qusyairy, Risalah Qusyairyah: Induk Ilmu

Tasawuf, Terj. Mohammad Luqman Hakiem, 218.

35 as-Sarraj, Al-Luma': Rujukan Lengkap Ilmu Tasawuf.

\section{Mahabbab (Cinta)}

Sahl bin Abdullah tentang mahabbah mengatakan bahwa mababbah adalah kecocokan hati dengan Allah SWT. dan senantiasa cocok dengan-Nya, beserta Nabinya. dengan senantiasa mencintai yang sangat mendalam untuk selalu berdzikir dan mengingat Allah SWT. dan menemukan manisnya bermunajat kepada Allah SWT. ${ }^{36}$ Kondisi spiritual mababbah bagi seorang hamba adalah melihat dengan kedua matanya terhadap nikmat yang Allah berikan kepadanya, dan dengan hati nuraninya dia melihat kedekatan Allah dengannya, segala perlindungan, penjagaan dan perhatian-Nya yang dilimpahkan kepadanya. ${ }^{37}$ Rabiah al Adawiyyah al-Basriyyah (wafat $185 \mathrm{H}$ / 801 M) dianggap sebagai Sufi pertama yang menyatakan cintanya kepada Allah dan mengemukakan teori komprehensif tentang Cinta Ilahi. ${ }^{38}$ Cinta bagi Rabi'ah sukar didefinisikan, karena cinta berisi perasaan kerinduan kepada yang dicinta.Meski demikian, Rabi'ah telah membuat rumusan analisis melalui serangkaian syair-syairnya yang sangat terkenal, sebagai berikut:

\section{Aku mencintai-Mu dengan dua cinta \\ Cinta karena diriku dan cinta karena Diri-Mu \\ Cinta karena diriku \\ Adalab keadaanku yang senantiasa mengingat-Mu \\ Cinta karena Diri-Mu \\ Adalah Keadaan-Mu menyingkapkan tabir hingga \\ Engkan kulihat \\ Bagiku, tidak ada puji untuk ini dan itu. \\ Tapi sekalian puji hanya bagiMu selalu ${ }^{39}$}

\section{Khauf (Takut)}

Khauf dalam tasawuf adalah hadirnya perasaan rasa takut ke dalam diri seorang salik

\footnotetext{
36 as-Sarraj, 119-20.

37 as-Sarraj, 120.

${ }^{38}$ Hassan Abu Hanieh, Sufism and Sufi Orders: God's Spiritual Paths: Adaptation and Renewalin the Context of Modernization (Jordan: Friedrich-Ebert-Stiftung, 2011), 70.

39 Asfari and Otto Sukatno, Mababbah Cinta: Mengarungi Samudera Cinta Rabi'ah Al-Adawiyah (Yogyakarta: Pustaka Hati, 2018), 52.
} 
(orang yang menuju Tuhan) karena dihantui oleh perasaan dosa dan ancaman yang akan menimpanya. Seorang yang berada dalam khauf akan merasa lebih takut kepada dirinya sendiri, sebagaimana ketakutannya kepada musuhnya. Saat khauf menghampirinya, dia merasa tentram dan tenang karena kondisi hatinya semakin dekat dengan Allah. ${ }^{40}$ Al-Junaid pernah ditanya mengenai takut ia menjawab, "takut adalah datangnya deraan dalam setiap hembusan nafas." Dzun Nuun al-Mishri juga berkomentar tentang takut, "manusia akan tetap berada di jalan selama takut tidak tercabut dari kalbu, sebab jika telah hilang dari kalbu mereka, maka mereka akan tersesat." Sedangkan Hatim al-Asham juga menjelaskan, "setiap sesuatu ada perhiasannya dan perhiasan ibadah adalah takut.Tanda takut adalah membatasi keinginan." ${ }^{41}$ Dengan demikian, khauf adalah kondisi spiritual di mana seorang sufi takut jika Allah tidak meliriknya sehingga mendekat pada-Nya.

\section{Raja' (harapan)}

Raja' atau harapan adalah memperhatikan kebaikan dan selalu berharap untuk dapat mencapainya, dan melihat berbagai bentuk kelembutan dan kenikmatan dari Allah, dan memenuhi diri dengan harapan demi masa depan serta hidup demi meraih harapan tersebut. ${ }^{42}$ Dzun Nun al-Mishry saat menjelang ajalnya dia berkata: "janganlah kalian memperdulikan aku, sebab aku telah terpersona oleh kelembutan Allah SWT. kepada diriku." Sedangkan Yahya bin Mu'adz berkata, "wahai Tuhanku, anugerahkanlah untukku yang termanis dalam hati berupa harapan kepada-Mu. Kata-kata paling sedap yang keluar dari lidahku berupa pujian kepada-Mu. Saat yang

\footnotetext{
${ }^{40}$ Rifi and Mud'is, Filsafat Tasawnf, 224.

41 al-Qusyairy, Risalah Qusyairyah: Induk Imu Tasawuf, Terj. Mohammad Luqman Hakiem, 126.

${ }^{42}$ Zaprulkhan, Ilmu Tasawuf: Sebuah Kajian Tematik. (Jakarta: Rajawali Pers, 2016), 64.
}

kuanggap paling berharga adalah saat aku akan berjumpa dengan-Mu". ${ }^{3}$

Raja' menuntut tiga perkara, yaitu (1) Takut harapannya itu hilang. (2) Berusaha untuk mencapainya. (3) Cinta kepada apa yang diharapkannya. ${ }^{44}$ Raja' terbagi menjadi tiga tingkatan; pertama, berharap kepada Allah (fillab). Kedua, berharap pahala dari Allah. Ketiga, berharap keluasan rahmat dari Allah.

\section{Uns (Suka Cita)}

Uns yaitu keadaan spiritual seorang sufi yang merasa intim atau akrab dengan Tuhannya, karena telah merasakan kedekatan denganNya.'Uns adalah keadaan spiritual saat qalbu dipenuhi rasa cinta, kelembutan, keindahan, belas kasih, dan ampunan dari Allah. ${ }^{45}$ Uns (bersuka cita) dengan Allah bagi seorang hamba adalah tingkatan paripurna kesuciannya dan kejernihan dzikirnya, sehingga dia merasa cemas, takut dan gelisah dengan segala sesuatu yang melupakannya untuk mengingat Allah. Maka pada saat itulah ia sangat bersuka cita dengan Allah SWT. ${ }^{46}$ Seseorang yang berada pada kondisi spiritual Uns akan merasakan kebahagiaan, kesenangan, kegembiraan, serta sukacita yang meluap-luap. Kondisi spiritual seperti ini dialami oleh seorang sufi ketika merasakan kedekatan dengan Allah. Yang mana, hati dan perasaannya diliputi oleh cinta, kelembutan, keindahan, serta kasih sayang yang luar biasa, sehingga sangat sulit untuk dilukiskan. ${ }^{47}$ Dengan demikian 'Uns adalah kondisi spiritual yang mana seorang sufi

43 al-Qusyairy, Risalah Qusyairyah: Induk Ilmu Tasawuf, Terj. Mohammad Luqman Hakiem, 135.

${ }^{44}$ Solihin and Anwar, Ilmu Tasawuf, 85.

45 Fahruddin, "Tasawuf Sebagai Upaya Membersikan Hati Guna Mencapai Kedekatan Dengan Allah," Jurnal Pendidikan Agama Islam Ta'lim 14, no. 1 (2016): 80 .

Tasawuf, 135

46 as-Sarraj, Al-Luma': Rujukan Lengkap Ilmu

${ }^{47}$ Hasyim Muhammad, Dialog Antara Tasawuf Dan Psikologi: Telaah Atas Pemikiran Psikologi Humanistik Abraham Maslow (Yogyakarta: Pustaka Pelajar, 2002), 53-54. 
merasakan kesukacitaan hati atau kebahagiaan hati karena bisa akrab dengan Tuhannya.

\section{Yakin}

Secara terminologi yakin adalah yaitu sebuah kepercayaan (Aqidah) yang kuat dan tidak mudah goyah dengan kebenaran dan pengetahuan yang dimilikinya, karena kesaksiannya dengan segenap jiwanya dan dirasakan oleh seluruh ekspresi tubuhnya, serta disaksikan oleh segenap eksistensinya. Adapun definisi lain dari yakin yaitu selamat dari keraguan dan syubhat, serta penguasaan atas pengetahuan yang akurat, tepat, dan benar, tanpa mengandung keraguan sama sekali. ${ }^{48}$ Sedangkan menurut al-Junaid "yakin merupakan kemantapan ilmu yang tidak dapat diubah dan tidak pula diganti serta tidak berubah apa yang ada di dalam hati". Yakin membuat seorang sufi selalu siap mengemban beban dan mengahadapi bahaya serta mendorongnya untuk maju terus ke depan. Jika yakin tidak disertai ilmu, maka dia membawanya kepada kehancuran, sedangkan ilmu menyuruhnya untuk mundur ke belakang, dan jika ilmu tidak disertai yakin, maka pelakunya tidak mau bergerak dan tidak mau berusaha dan pasif. $^{49}$

Para sufi biasanya membagi yakin dalam tiga bagian: pertama, Ilm al-yaqin: yaitu pencapaian iman dan ketundukan terkuat yang berhubungan dengan hal-hal yang ingin dicapai dengan memperhatikan dalil-dalil dan petunjuk yang jelas dan benar. Kedua, 'Ain al-yaqin: yaitu pencapaian makrifat melampaui batasan definisi yang dilakukan oleh ruh melalui penyingkapan, musyahadah, persepsi dan kesadaran. Ketiga, Haqq al-yaqin: yaitu anugerah yang berupa bersamaan (ma'iyyah) yang mengandung banyak rahasia, tanpa tirai dan penghalang, yang melampaui imajinasi

48 Gulen, Tasawuf Untuk Kita Semua: Menapaki Bukit-Bukit Zamrud Kalbu Melalui Istilah-Istilah Dalam Praktik Sufisme, 225.

49 Al-Jauziyah, Madarijus Salikin: Pendakian Menuju Allah Penjabaran Konkrit "Iyyaka Na'budu Wa Iyyaka Nasta'in,"352-53. manusia serta tanpa kammiyyah ataupun kaifiyyah. Sebagian sufi menafsirkan yang satu ini sebagai fana' sang hamba pada seluruh jati diri, ego, diri, dan kebersamaannya kepada Allah alHaqq. $^{50}$

\section{RELEVANSI TASAWUF}

Setiap manusia khususnya yang beragama Islam tentunya ingin dekat dengan Tuhannya Allah SWT. Ada begitu banyak jalan untuk bisa dekat dengan Allah SWT, salah satunya adalah dengan jalan tasawuf. J. Spencer Trimingham penulis buku The Sufi Orders in Islam mengatakan bahwa setiap manusia mungkin baginya untuk memiliki pengalaman langsung dengan Tuhan jikalau ia mau untuk menempatkan dirinya untuk mempraktekan ajaran tasawuf. ${ }^{51}$ Ini artinya siapa saja bisa memiliki pengalaman dengan Tuhan, tanpa terkecuali.Dalam jurnal yang ditulis oleh "Arif Zamhari mengatakan bahwa tradisi sufi telah tumbuh secara signifikan di dunia Muslim modern, termasuk Indonesia". Saat ini, sufisme tidak hanya dipraktikkan oleh penduduk desa, petani, dan orang-orang yang tidak berpendidikan, tetapi juga dipraktekkan oleh kaum urban, elit nasional, dan orang-orang berpendidikan. Apalagi, sufisme sudah mengalami inovasi yang signifikan dalam hal prakteknya dan organisasi. $^{52}$

Perlunya ajaran tasawuf dalam kehidupan sehari-hari karena tidak lepas dari adanya dua unsur yang saling melengkapi, yaitu unsur lahir dan unsur batin. Unsur lahir diwakili oleh syari'ah,

50 Gulen, Tasawnf Untuk Kita Semua: Menapaki Bukit-Bukit Zamrud Kalbu Melalui Istilah-Istilah Dalam Praktik Sufisme, 229.

51 J. Spencer Trimingham, The Sufi Orders in Islam (London: Oxford University Press, 1971), 1; Martin Van Bruinessen, Kitab Kuning, Pesantren, Dan Tarekat: TradisiTradisi Islam Di Indonesia (Bandung: Mizan, 1995).

${ }^{52}$ Arif Zamhari, "Socio-Structural Innovations in Indonesia's Urban Sufism: The Case Study of the Majelis Dzikir and Shalawat Nurul Mustafa," Journal of Indonesian Islam 7, no. 1 (2013): $119-44$, https://doi.org/10.15642/JIIS.2013.7.1.119-144; Julia Day Howell, "Sufism and the Indonesian Islamic Revival," The Journal of Asian Studies 60, no. 3 (2001): 701-29. 
sementara unsur batin diwakili oleh haqiqah. Syariah merupakan pintu masuk untuk menuju haqiqah, dan haqiqah merupakan tujuan dari pelaksanaan syri'ah. ${ }^{53}$ Perbedaan antara syari'ab dan haqiqah dapat diibaratkan seperti kulit dan isi atau lingkaran dan titik tengahnya. Rene Guenon, seorang tokoh ternama dalam mistisisme Kristen yang kemudian masuk Islam melalui pendekatan sufisme, dia mengatkan bahwa antara syari'ab dan haqiqah tidak dapat dipisahkan. Demikian pula dengan Abu A'li al-Daqqaq berpendapat bahwa antara yang syariah dan haqiqah tidak bisa dipisahkan dalam Islam. Ia menggambarkan dengan ayat, bahwa ayat "iyyaka na'bud" sebagai ayat yang berkonotasi syari'ah, sementara "iyyaka nasta'in" sebagai ayat yang berkonotasi haqiqah.

Melihat kepada maqamat tasawuf dinilai relevansinya dengan perkembangan zaman. Mulai dari taubat, wara', zuhud, fakir, sabar, tawakkal dan ridha. Taubat dalam tasawuf yang menghendaki manusia agar senantiasa memperbaiki diri dari kekhilafan-kekhilafan yang terjadi senantiasa istighfar dan intropeksi diri. Dalam kajian sufistik, ada tiga syarat taubat yang harus dipenuhi: pertama, dia harus berniat dengan sunguh-sunguh untuk tidak mengulangi perbuatan itu kembali. Kedua, dia harus menghentikan maksiatnya. Ketiga, dia harus menyesali perbuatan yang terlanjur dilakukannya. ${ }^{54}$ Titik puncak atau klimaks dari bertaubat adalah awbah, setelah melalui fase taubah dan inabah. Taubah adalah taubat karena takut akan siksa Allah. Inabah adalah taubat karena mengharap pahala Allah. Sedangkan taubah adalah bertaubat karena Allah, tak berharap mendapat surga atau dijauhkan dari neraka. ${ }^{55}$ Dengan demikian maqamat taubat merupakan jenjang pertama untuk menuju kedekatan hakiki dengan Allah.

\footnotetext{
${ }^{53}$ Rifi and Mud'is, Filsafat Tasawuf, 56.

${ }^{54}$ Isa, Hakekat Tasawnf, 195.

55 Owobo, 50 Komike Sufi: Cara Asyik Menyimak Kisah Hikmah, Dan Ajaran Tasawnf (Jakarta: Zaman, 2014), 46.
}

Begitu halnya dengan wara', melihat perkembangan zaman yang semakin hari semakin banyak ditemukan hal-hal yang kejelasannya diragukan, maka adanya wara' hendaknya menjadikan sufi khususnya dan manusia umumnya untuk waspada dan berhati-hati bahkan meninggalkan perkara-perkara syubhat. Sikap menjauhi diri dari yang syubbat ini sejalan dengan hadits Nabi yang artinya: "Barangsiapa yang dirinya terbebas dari syubhat, maka sesungguhnya ia telah terbebas dari yang haram." (H.R. Bukhari). Hadits tersebut menunjukkan bahwa syubhat lebih dekat pada yang haram. Kaum sufi menyadari benar bahwa setiap makanan, minuman, pakaian, dan sebagainya yang haram dapat memberi pengaruh bagi orang yang memakan, meminum dan memakannya. Orang yang demikian akan keras hatinya, sulit mendapatkan hidayah dan ilham dari Tuhan.

Hal ini dipahami dari hadits Nabi yang menyatakan bahwa setiap makanan yang haram yang dimakan oleh manusia akan menyebabkan noda hitam pada hati yang lama-kelamaan hati menjadi keras. Hal ini sangat ditakuti oleh para sufi yang senantiasa mengharapkan Nur Illahi yang dipancarkan lewat hatinya yang bersih. ${ }^{56}$ Demikian dengan zuhud, zuhud zaman milenial adalah zuhud semangat untuk berjuang, yang menghendaki manusia agar bisa mengapai dunia, namun hal itu sama sekali tak melalaikan kedekatannya dengan Tuhan.

Adapun Menurut Ibnu 'Athaillah alSakandariada "dua tanda seseorang yang zuhud terhadap dunia, yaitu tanda ketika memiliki harta dan tanda ketika tidak memiliki harta. Ketika memiliki harta, seorang zahid selalu mendahulukan orang lain, dan ketika tidak tidak memilikinya, dia selalu bersikap lapang dan menerima". Orang yang mendahulukan kepentingan orang lain berarti mensyukuri nikmat keberadaan, dan orang yang merasa lapang ketika

${ }^{56}$ Nata, Akblak Tasawnf Dan Karakter Mulia, 17273. 
tidak punya berarti mensyukuri nikmat ketiadaan. Itulah buah pemahaman dan makrifat.Sebab, anugerah Allah tidak hanya berupa pemberian harta, Dia tidak memberipun merupakan salah satu bentuk anugerah-Nya.Bahkan, ketika tidak memberi, nikmat-Nya menjadi lebih sempurna. ${ }^{57}$ Maqamat zuhud ini bisa dikatakan sebagai kedudukan spiritual yang menghendaki agar seorang sufi meraih kedekatan kepada Tuhan dengan jalan hidup di dunia tanpa ternodai dan terpengaruh sedikitpun.

Fakir dalam tasawuf bukan berarti fakir harta atau tidak butuh pada harta, melainkan fakir yang dimaksud adalah butuh akan kehadiran Allah, sehingga selalu mengantungkan segala kehidupan pada Allah.Ibrahim bin Ahmad alKhawwash mengatakan: "kefakiran itu selendang kemuliaan, pakaian para rasul, jubbah orangorang sholeh, mahkota orang-orang yang bertakwa, perhiasan orang-orang mukmin, harta jarahan perang orang-orang arif, harapan para murid, benteng-benteng orang yang taat, penjara orang-orang yang berdosa, penghapus kejelekan, pelipatganda kebaikan, pengangkat kuasa, kemuliaan (karamah) bagi orang-orang baik yang menjadi Wali-Nya". Kefakiran adalah tanda simbol orang-orang saleh dan kebiasaan orangorang yang bertaqwa. ${ }^{58}$ Menurut Abu Nasrh asSarraj maqamat fakir memiliki "tiga tingkatan: pertama, orang yang tidak memiliki apa-apa dan tidak meminta apapun kepada seseorang, baik secara lahir maupun batin. Kedua, orang yang tidak memiliki apapun. Namun ia tidak meminta kepada siapapun, tidak mencari dan juga tidak memberi isyarat atas kefakirannya. Ketiga, tidak memiliki apa-apa. Jika ia membutuhkan sesuatu ia akan mengungkapkannya kepada sebagian temannya yang dia kenal, yang mana bila dia mengungkapkan kepadanya dia akan merasa

57 Ibn 'Athaillah al-Sakandari, Terapi Makrifat Misteri Berserah Kepada Allah (Jakarta: Zaman, 2011), 143. Tasawnf, 98-99. senang". ${ }^{59}$ Dari penjelasan di atas dapat dipahami bahwa maqamat tasawuf adalah sebuah kedudukan spiritual penghambaan seorang sufi bahwa yang dibutuhkannya hanyalah Allah semata.

Dalam Hidup tidak cukup dengan doa saja tawakkal menjadi bagian dari tercapainya apa yang kita minta kepada Allah. Tawakkal dalam tasawuf merupakan semangat juang dalam kehidupan manusia, agar senantiasa berusaha dulu, setelah itu serahkan hasilnya kepada Allah, hal ini tentunya sesuai dengan karekteristik masyarakat modern yang cenderung giat bekerja, namun mengantungkan hasilnya kepada Allah SWT. Al-Ghazali dan Ibnu Ujaibah membagi tawakal ke dalam tiga tingkatan: "pertama, tingkatan yang paling rendah, yaitu engkau bersama Allah, sebagaimana halnya muwakkil (orang yang mewakkilkan) bersama wakilnya yang baik dan ramah. Kedua, tingkatan pertengahan, yaitu engkau bersama Allah, sebagaimana halnya seorang anak bersama ibunya. Seorang anak tidak akan mencurahkan segala urusannya kecuali kepada ibunya. Ketiga, tingkatan yang paling tinggi, yaitu engkau bersama Allah, sebagaimana halnya orang yang sakit di hadapan dokternya". Adapun perbedaan antara tingkatan-tingkatan ini adalah bahwa pada tingkatan pertama, kadang-kadang dalam pikirannya terdetik sebuah kecurigaan. Pada tingkatan kedua, tidak ada kecurigaan, akan tetapi dia akan selalu bergantung pada ibunya ketika dia sedang membutuhkan sesuatu. Adapun pada tingkatan ketiga, tidak ada kecurigaan dan ketergantungan pada yang lain, karena dirinya telah fana dan setiap waktu dia melihat apa yang dilakukan Allah terhadapnya. ${ }^{60}$ Dengan demikian dapat dipahami bahwa maqamat tawakkal adalah kedudukan spiritual seorang sufi yang menghendaki adanya ketergantungan dan mewakilkan segala urusan hanya pada Allah semata.

\footnotetext{
59 as-Sarraj, 99-100.

${ }^{60}$ Isa, Hakekeat Tasawnf, 265-66.
}

Tasawuf dan Problematika Modernitas... 
Tujuan dalam hidup ini salah satunya mendapatkan ridha Allah. Penting untuk memiliki sifat ridha kiranya, dikarenakan lika-liku kehidupan yang jika tidak ada keridhaan di dalamnya maka yang akan muncul adalah rasa berkeluh kesah, msyarakat modern yang saat ini berpatokan pada kemampuan akalnya jika tidak memiliki keridahan dalam hidup maka gejala stress akan menghampiri dirinya. Dzun Nun alMishri menyatakan, "tanda-tanda ridha ada tiga: “(1) tindakan sang hamba meninggalkan keinginannya karena mengutamakan keinginan Allah SWT. sebelum ia melakukan sesuatu. (2) Pengetahuan sang hamba bahwa yang terbaik adalah yang dipilih oleh Allah setelah ia melakukan sesuatu. (3) Tidak gelisah serta tetap mencintai Allah ketika sang hamba berada di tengah musibah". ${ }^{61}$ Buah dari ridha adalah munculnya kesenangan dan ketenangan menakjubkan yang berembus dari keridhaan Allah SWT. yang berpadu secara langsung dengan besarnya cita-cita dan harapan yang dimiliki seorang hamba. Dari paparan di atas dapat disimpulkan bahwa maqamat ridha adalah kedudukan spiritual di mana seorang sufi hanya melihat kebahagiaan segala apa yang terjadi padanya karena adanya rasa rela pada dirinya.

Adapun abwal tasawuf atau kondisi spiritual yang dirasakan oleh seorang sufi dalam pendekatkan diri kepada Allah, tentu adalah sebuah kondisi spiritual yang diimpi-impikan oleh seorang sufi untuk bisa merasakannya. Hal sebagai sebuah kondisi yang singgah dalam kalbu, merupakan efek dari peningkatan maqamat seseorang. Secara teoritis, memang bisa dipahami bahwa kapanpun seorang hamba mendekat kepada Allah dengan cara berbuat kebajikan, ibadah, riyadhah, dan mujabadah, maka Allah akan memanifestasikan diri-Nya dalam kalbu hamba tersebut. $^{62}$ Kondisi seperti ini tentu akan tetap

61 Gulen, Tasawuf Untuke Kita Semua: Menapaki Bukit-Bukit Zamrud Kalbu Melalui Istilah-Istilah Dalam Praktik. Sufisme, 202.

62 Bahri, Tasawuf Mendamaikan Dunia, 90. relevan dengan kehidupan manusia selama manusia masih beragama, pengalaman dengan Tuhan tentu adalah hal yang diinginkan, apalagi itu adalah sebuah pemberian atau anugerah dari Allah.

Sedangkan hal kata jamak dari abwal artinya suasana atau keadaan yang menyelimuti qalbu, yang diciptakan sebagai hak prerogatif Allah dalam hati setiap hambanya, tidak ada sufi yang mampu merubah keadaan tersebut apabila dating saatnya, atau memperhatikannya apabila pergi. ${ }^{63}$ Intinya adalah diperkenalkan dengan maksud sebagai bagian pentinnya tasawuf yang tujuannya perjalanan spiritual baik itu pemahaman tentang Allah, keridhaanya.

\section{PENUTUP}

Maqamat dan ahwal dua hal yang berbeda tetapi memiliki hubungan. Dikatakan berbeda karena maqamat adalah kedudukan spiritual seorang hamba yang diupayakan dengan sungguhsungguh dan komitmen yang kuat serta istiqamah sehingga mencapai puncak dari maqamat tersebut. Adapun abwal adalah kondisi spiritual seorang sufi yang memiliki pengalaman dengan Allah yang dia tidak diusahakan namun merupakan sebuah pemberian dari Tuhan. Maqamat dan abwal adalah konsep subjektif yang masing-masing sufi memiliki pandangannya tersendiri dan jumlah kuantitasnya. Dalam kajian ini maqamat dan ahwal yang ditampilkan adalah menurut $\mathrm{Abu}$ Nashr as-Sarraj pengarang kitab Al-Luma': Rujukan Lengkap Ilmu Tasawuf, yang mana maqamat itu ada tujuh yaitu: taubat, wara, zuhud, fakir, sabar, tawakal, dan ridha. Adapun ahwal adalah muraqabah, mahabbah, khauf, raja', syauq, 'uns, tuma'ninah, musyahadah, dan yakin. Adapun relevansi konsep-konsep tasawuf dengan kehidupan sekarang adalah bahwasanya konsepkonsep tersebut akan menjadi suatu pedoman bagi umat manusia untuk mencapai kedekatan yang hakiki dengan Allah SWT. Dan bisa menjadi

\footnotetext{
${ }^{63}$ Nata, Akblak Tasawuf Dan Karakter Mulia, 177.
} 
acuan untuk meneliti lebih mendalam lagi mengenai tasawuf.

\section{DAFTAR KEPUSTAKAAN}

Abu Hanieh, Hassan. Sufism and Sufi Orders: God's Spiritual Paths: Adaptation and Renewalin the Context of Modernization. Jordan: FriedrichEbert-Stiftung, 2011.

Al-Jauziyah, Ibnu Qayyim. Madarijus Salikin: Pendakian Menuju Allab Penjabaran Konkrit 'Tyyaka Na'budu Wa Iyyaka Nasta'in.” Jakarta: Pustaka al-Kautsar, 2017.

al-Qusyairy, Imam. Risalah Qusyairyab: Induk Imu Tasawuf, Terj. Mohammad Luqman Hakiem. Surabaya: Risalah Gusti, 2014.

al-Sakandari, Ibn 'Athaillah. Terapi Makrifat Misteri Berserah Kepada Allah. Jakarta: Zaman, 2011.

Annemarie Schimmel. Mystical Dimensions of Islam. North Carolina: The University of North Carolina Press, 1975.

as-Sakandari, Syaikh Ibn 'Atha'illah. Kitab AlHikam: Petuah-Petuah Agung Sang Guru, Terj. Ismail Ba'adillah. Jakarta: Khatulistiwa Press, 2012.

as-Sarraj, Abu Nashr. Al-Luma': Rujukan Lengkap Ilmu Tasawnf. Surabaya: Risalah Gusti, 2002.

Asfari, and Otto Sukatno. Mababbab Cinta: Mengarungi Samudera Cinta Rabiah AlAdawiyah. Yogyakarta: Pustaka Hati, 2018.

Bagir, Haidar. Buku Saku Tasawnf. Bandung: Mizan, 2005.

Bahri, Media Zainul. Tasamuf Mendamaikan Dunia. Jakarta: Erlangga, 2010.

Bruinessen, Martin Van. Kitab Kuning, Pesantren, Dan Tarekat: Tradisi-Tradisi Islam Di Indonesia. Bandung: Mizan, 1995.

Dhavamony, Mariasusai. Fenomenologi Agama. Yogyakarta: Penerbit Kanisius, 1995.

Fahruddin. "Tasawuf Sebagai Upaya Membersikan Hati Guna Mencapai Kedekatan Dengan Allah." Jurnal Pendidikan Agama Islam Ta'lim 14, no. 1 (2016): 80.

Gulen, Muhammad Fethullah. Tasawuf Untuk Kita Semua: Menapaki Bukit-Bukit Zamrud Kalbu Melalui Istilah-Istilah Dalam Praktik Sufisme. Jakarta: Republika, 2013.

Hamka. Tasawuf Modern: Bahagia Itu Dekat Dengan Kita Ada Di Dalam Diri Kita. Jakarta: Republika, 2015.

Howell, Julia Day. "Sufism and the Indonesian
Islamic Revival." The Journal of Asian Studies 60, no. 3 (2001): 701-29.

Irawan, Dedy. "Tasawuf Sebagai Solusi Krisis Manusia Modern: Analisis Pemikiran Seyyed Hossein Nasr." Tasfiyah 3, no. 1 (February 2019): 41. https://doi.org/10.21111/tasfiyah.v3i1.2981

Isa, Syaikh 'Abdul Qadir. Hakekat Tasawnf. Jakarta: Qisthi Press, 2005.

Muhammad, Hasyim. Dialog Antara Tasawnf Dan Psikologi: Telaah Atas Pemikiran Psikologi Humanistik Abraham Maslow. Yogyakarta: Pustaka Pelajar, 2002.

Nata, Abuddin. Akblak Tasawuf Dan Karakter Mulia. Jakarta: Rajawali Pers, 2013.

Owobo. 50 Komik Sufi: Cara Asyik Menyimak Kisah Hikmah, Dan Ajaran Tasawnf. Jakarta: Zaman, 2014.

Putra, Apria. "Ulama Dan Karya Tulis: Diskursus KeIslaman Di Minangkabau Awal Abad 20.” Fuaduna: Jurnal Kajian Keagamaan Dan Kemasyarakatan 1, no. 2 (2017): 134-47. https://doi.org/http://dx.doi.org/10.30983 / fuaduna.v1i2.434.

Rifi, Bahrun, and Hasan Mud'is. Filsafat Tasawnf. Bandung: CV Pustaka Setia, 2010.

Solihin, M., and Rosihon Anwar. Ilmu Tasawuf. Bandung: CV Pustaka Setia, 2008.

Syata, As-Sayid Abu Bakar Ibn Muhammad. Menapak Jejak Kaum Sufi. Surabaya: Dunia Ilmu, n.d.

Taufik, Zulfan. "The Youth and The Primacy against Religious Radicalism through the Organization of Mahasiswa Ahlith Thariqah Al Mu'tabarah An Nahdliyyah (MATAN) in Indonesia." TEOSOFI: Jurnal Tasawnf Dan Pemikiran Islam 9, no. 1 (June 1, 2019): 109_ 30.

https://doi.org/10.15642/teosofi.2019.9.1.1 09-130.

Tohir, Moenir Nahrowi. Menjelajah Eksistensi Tasawnf Meniti Jalan Menuju Tuhan. Jakarta: PT As-Salam Sejahtera, 2012.

Trimingham, J. Spencer. The Sufi Orders in Islam. London: Oxford University Press, 1971.

Yunus, Mahmud. Kamus Arab. Jakarta: Hidakarya Agung, 1990.

Zahri, Mustafa. Kunci Memahami Ilmu Tasawuf,. Surabaya: PT Bina Ilmu, 1979. 
Zamhari, Arif. "Socio-Structural Innovations in Indonesia's Urban Sufism: The Case Study of the Majelis Dzikir and Shalawat Nurul Mustafa." Journal of Indonesian Islam 7, no. 1 (2013): 119-44.

https://doi.org/10.15642/JIIS.2013.7.1.119144.

Zaprulkhan. Ilmu Tasawuf: Sebuah Kajian Tematik. Jakarta: Rajawali Pers, 2016. 